\title{
Review \\ Altered Task-Evoked Corticolimbic Responsivity in Generalized Anxiety Disorder
}

\author{
Nayoung Kim ${ }^{1}$ and M. Justin Kim ${ }^{1,2, *}$ \\ 1 Department of Psychology, Sungkyunkwan University, Seoul 03063, Korea; kimannie0826@gmail.com \\ 2 Center for Neuroscience Imaging Research, Institute for Basic Science, Suwon 16060, Korea \\ * Correspondence: minuekim@skku.edu
}

check for updates

Citation: Kim, N.; Kim, M.J. Altered Task-Evoked Corticolimbic Responsivity in Generalized Anxiety Disorder. Int. J. Mol. Sci. 2021, 22, 3630. https://doi.org/10.3390/ ijms22073630

Academic Editor: Zoya Marinova

Received: 13 January 2021

Accepted: 26 March 2021

Published: 31 March 2021

Publisher's Note: MDPI stays neutral with regard to jurisdictional claims in published maps and institutional affiliations.

Copyright: (c) 2021 by the authors. Licensee MDPI, Basel, Switzerland. This article is an open access article distributed under the terms and conditions of the Creative Commons Attribution (CC BY) license (https:/ / creativecommons.org/licenses/by/ $4.0 /)$.

\begin{abstract}
Generalized anxiety disorder (GAD) is marked by uncontrollable, persistent worry and exaggerated response to uncertainty. Here, we review and summarize the findings from the GAD literature that employs functional neuroimaging methods. In particular, the present review focuses on task-based blood oxygen level-dependent (BOLD) functional magnetic resonance imaging (fMRI) studies. We find that select brain regions often regarded as a part of a corticolimbic circuit (e.g., amygdala, anterior cingulate cortex, prefrontal cortex) are consistently targeted for a priori hypothesis-driven analyses, which, in turn, shows varying degrees of abnormal BOLD responsivity in GAD. Data-driven whole-brain analyses show the insula and the hippocampus, among other regions, to be affected by GAD, depending on the task used in each individual study. Overall, while the heterogeneity of the tasks and sample size limits the generalizability of the findings thus far, some promising convergence can be observed in the form of the altered BOLD responsivity of the corticolimbic circuitry in GAD.
\end{abstract}

Keywords: generalized anxiety disorder; amygdala; prefrontal cortex; corticolimbic circuit; fMRI

\section{Introduction}

Generalized anxiety disorder (GAD) is characterized by uncontrollable, repetitive thoughts pertaining to negative emotions-in other words, excessive worry [1]. Patients with GAD suffer from heightened sensitivity to uncertainty and unpredictability, which are well-known sources of stress [2]. Indeed, GAD patients report higher levels of stress from daily life events compared to healthy individuals [3], and, conversely, stress reduction programs effectively reduce anxiety symptoms in GAD [4].

As with many other psychiatric disorders, researchers have sought to discover and develop potential brain-based biomarkers for GAD via structural and functional neuroimaging methods [5]. Magnetic resonance imaging (MRI), in particular, offers a non-invasive means to measure diverse properties of the human brain, including regional volume, functional responsivity to psychological tasks, functional architecture at rest, and connectivity. Naturally, an abundance of MRI studies of GAD has been made available over the past 20 years (see $[6,7]$ for recent reviews of the literature).

Among them, we specifically focus on the findings from task-based functional magnetic resonance imaging (fMRI) experiments. These studies employ psychological tasks in the scanner, and the subject's blood oxygen level-dependent (BOLD) signals are acquired as estimates of brain activity while they are performing the tasks. The rationale for our decision to focus on neuroimaging studies of GAD using task-based fMRI is twofold. First, unlike structural MRI or resting-state fMRI studies, task-based fMRI studies are much more diverse and heterogeneous, as the outcomes are dependent on the nature of the tasks used in the experiment. Thus, a closer look at the task-based fMRI literature is necessary in order to draw general conclusions about potential brain-based biomarkers of GAD. Second, important critiques on the usage of task-based fMRI research in clinical neuroscience have emerged recently. These include overall power issues in the literature due to small sample 
sizes [8] and the poor test-retest reliability of BOLD signals under certain conditions $[9,10]$. In light of this, a careful examination of the existing task-based fMRI studies of GAD would prove to be useful, especially for offering guidelines for future investigations.

Here, we will begin by offering a summary of a popular neurobiological framework for anxiety: the dysregulation of emotion due to an abnormal corticolimbic circuit that centers on the amygdala [11-13]. As we will discuss in more detail below, many task-based fMRI studies of GAD have adopted this framework and specifically targeted the amygdala and other components of the corticolimbic circuit. Elucidating how different tasks evoke different corticolimbic responses in GAD would be a key first step in advancing biomarker development for GAD.

\section{Neural Circuitry for Emotional Reactivity and Regulation}

Affective neuroscience research has consistently focused on the amygdala and elucidated its functional role in various aspects of emotional processing [14]. This trend continued when fMRI became widely available as a non-invasive neuroimaging tool for surveying the human brain [15] based on two lines of prior research: fear conditioning in animals [16] and studying patients with amygdala lesions [17]. Both lines of work highlight the functional importance of the amygdala in processing fear and, as an extension, provide a possible neurobiological mechanism for pathological anxiety [18]. Human fMRI studies have since offered a more nuanced explanation for the involvement of the amygdala in various aspects of emotion, such as negative affect [19], full range of valence [20], arousal [21], and socially salient information [22]. Importantly, the amygdala does not operate in isolation; rather, it works in concert with interconnected brain areas that include the anterior cingulate cortex (ACC) and prefrontal cortex (PFC), which send and receive reciprocal signals via monosynaptic pathways $[23,24]$.

Relevantly, emotion regulation, or attempts at controlling or influencing emotional responses [25], has been suggested as a key transdiagnostic factor for psychopathology [26], and its underlying neural mechanisms have been studied extensively in the past two decades [27]. Not surprisingly, the amygdala and corticolimbic circuit have been suggested to be at the core of this psychological process, particularly the cognitive control of emotion [28]. fMRI research on cognitive control of emotion (i.e., cognitive reappraisal) typically aims to reduce amygdala responsivity to emotion-inducing stimuli [29], and several PFC regions have been shown to provide top-down regulatory input to the amygdala [30]. Naturally, the amygdala and corticolimbic circuit have been frequently targeted in fMRI studies of anxiety [13,31]. As such, understanding the characteristics of the corticolimbic circuit would serve as a useful prerequisite for reviewing altered BOLD signals in GAD patients.

\subsection{Neuroanatomy of the Corticolimbic Circuit}

We note that, while the term "corticolimbic circuit" may indicate any neural circuitry involving at least a pair of cortical and limbic components, we are using it to refer to a neural circuitry that consists of the amygdala and the prefrontal cortex (including the neighboring anterior cingulate cortex). In the literature, it is also referred to as the amygdala-prefrontal circuitry, the frontolimbic pathway, or frontoamygdalar connectivity. Regardless of the minor differences in nomenclature, a key functional characteristic of this corticolimbic circuit is the reciprocal relationship between the amygdala and PFC [28,32].

Most of what we know about the neuroanatomy of the amygdala, PFC, and their connectivity is due to animal studies. Tracing studies from non-human primate brains demonstrated that the majority of the efferent fibers from the amygdala project to the medial portion of the PFC, including the ventromedial (vmPFC) and dorsomedial prefrontal cortex (dmPFC), the neighboring anterior cingulate cortex (ACC), and the orbitofrontal cortex (OFC) $[23,33,34]$. Likewise, afferent projections from the PFC to the amygdala mostly originate from the vmPFC, dmPFC, and OFC $[23,34,35]$. This interconnectivity is what allows PFC neurons to control and regulate amygdala activity, and such cellular mechanisms have been identified from animal models of fear [36,37]. 


\subsection{Corticolimbic Circuit and Anxiety}

Human fMRI studies of normative and pathological anxiety have adopted this framework and hypothesized that greater anxiety would correspond to a hyperactive amygdala due to a hypoactive PFC [11]. Many anxiety disorder studies have found support for this prediction, particularly in the form of exaggerated amygdala BOLD signals in patient groups [38,39]. Reduced PFC and ACC BOLD signals as a function of normative anxiety [40] and PTSD diagnoses [41] were observed. Other fMRI studies examined the functional connectivity patterns of the corticolimbic circuit time series data and found a generally decreased coupling between the amygdala and PFC/ACC as a function of anxiety $[42,43]$. Overall, consistent with the functional neuroimaging literature of emotion regulation, anxiety was viewed as a condition where a failure to recruit PFC/ACC leads to a hyperactive amygdala - in other words, an imbalance of the corticolimbic circuit [13].

\section{Altered BOLD Responsivity in GAD}

Here, we summarize the findings from task-based fMRI studies of GAD that have been published until 2020. Literature search was conducted using the PubMed database, PsycINFO, and Google Scholar for papers reporting fMRI BOLD differences between generalized anxiety disorder patients and healthy controls, using the following keywords "GAD" AND "fMRI". Then, we manually identified studies employing task-based fMRI that reported task-evoked activations using stereotaxic coordinates in standard space (MNI or Talairach space) and removed any duplicates. After restricting the written language to English, a total of 45 studies were included. While these studies used a variety of tasks, the majority included an emotional component (e.g., facial expressions, affective images, emotionally charged videos, anxiety-inducing words, emotional Stroop task, and fear conditioning/extinction). Results from the literature are organized by neuroanatomical regions, focusing on the components of the corticolimbic circuit.

\subsection{Amygdala}

Many fMRI studies employed tasks with an emotional component (e.g., facial expressions, aversive images, and emotionally-charged videos) that aimed to target the amygdala. These studies mostly relied on targeted ROI analyses of the amygdala, based on a priori hypothesis that GAD patients would show an exaggerated amygdala response to emotional stimuli-particularly those associated with negative or aversive effects. For example, in an emotion regulation paradigm, GAD patients, compared to healthy controls, showed greater amygdala reactivity when instructed to view negative emotional images [44]. In response to negative vs. neutral words in an emotional Stroop task, GAD patients showed higher amygdala activity than healthy controls [45]. Generating worry topics also elicited greater amygdala activity in older ( $>60$ years of age) GAD patients [46]. During script-driven imagery, GAD patients exhibited increased amygdala activity in response to disorder-related scripts compared to healthy volunteers [47]. GAD patients showed exaggerated dorsal amygdala reactivity to cues that predict subsequent pictures, regardless of whether their contents were aversive or neutral [48]. However, a few other studies reported no such amygdala effects, or even attenuated amygdala activity in GAD patients [49-51].

The most popular type of emotional stimuli used to elicit amygdala reactivity in fMRI investigations of GAD was facial expressions. While task heterogeneity was evident across many studies (e.g., differences in the behavioral task, stimulus presentation, and emotional category used), the general pattern of findings pointed towards exaggerated amygdala BOLD response in GAD. For example, children diagnosed with GAD showed increased amygdala activity to fearful vs. happy faces [52] and to angry vs. neutral faces [53] compared to their healthy counterparts. Consistent with these findings from pediatric GAD patients, adult GAD patients also exhibited elevated amygdala activity in response to threat-related (fearful and angry) vs. non-threatening (happy) faces [54]. Interestingly, a subsequent study by the same group demonstrated that, when fearful and angry face conditions were separated, increased amygdala BOLD response in GAD was only observed 
for the fearful vs. happy face contrast [55]. In affective neuroscience research, due to the differences in the facial features and the emotional signals embedded within them, fearful faces are used to measure an individual's sensitivity to implicit environmental threat, whereas angry faces are used to index sensitivity to explicit interpersonal threat [56]. Here, of particular relevance to GAD symptomatology is that fearful faces are characterized by its inherent ambiguity with regard to the source of the threat-when we see another person expressing fear, we know about the presence of threat, but the source of that threat remains unclear [57]. This uncertainty may, in part, account for the observed exaggerated amygdala BOLD response to fearful faces that GAD patients exhibit. Finally, we note that one study reported increased amygdala activity to neutral faces in GAD patients [58]. However, one earlier study failed to observe exaggerated amygdala activity to fearful vs. neutral faces in GAD patients. In fact, a blunted amygdala response was found, as healthy volunteers showed greater amygdala activity to this contrast [59].

To summarize, task-based fMRI studies of GAD that employed an emotional task often set out to target the amygdala, on the premise of its hyper-responsivity to negative valence and/or threat-related stimuli. While there were a number of studies showing mixed findings, this prediction was supported overall.

\subsection{Anterior Cingulate Cortex}

Similar to studies targeting the amygdala, many fMRI experiments employed tasks with an emotional component that included the presentation of facial expressions, negative and positive images, worry-inducing sentences and items, and fear conditioning paradigm. Based on the known regulatory role of the ACC on the amygdala during affective processing [60], especially when cognitive control is involved [61], these studies sought out to test the hypothesis that GAD patients would display reduced ACC response to emotional (often threat-related) stimuli. For example, while viewing emotional faces, GAD patients, compared to healthy controls, showed diminished ACC reactivity to fearful vs. neutral faces [62,63] and happy vs. neutral faces [63]. In a study utilizing an emotion regulation paradigm, GAD patients showed dampened dorsal ACC responses when instructed to maintain their emotional responses to negative images [64]. Another emotion regulation study reported that GAD patients exhibited lower levels of dorsal ACC activity when instructed to downregulate their emotions to negative pictures [49]. In the same study, GAD patients showed decreased rostral ACC reactivity in the incongruent conditions of an emotional Stroop task [49]. Consistent with these findings, in a fear conditioning paradigm, GAD patients displayed lesser ACC activity to safety signals vs. threat signals compared to healthy controls [65]. It is worth noting, however, that there were a couple of studies reporting an opposite pattern - that is, exaggerated ACC reactivity in GAD patients compared to healthy controls [52,54]. Once again, these inconsistencies can be attributed to a wide range of factors, including task heterogeneity, age differences (adult vs. adolescent GAD), and small sample sizes.

Of note, a few studies utilizing worry-generating situations consistently showed enhanced ACC reactivity in GAD patients. For example, while performing a worry induction task with sentences and faces, GAD patients exhibited increased ACC reactivity to post-worry states compared to healthy controls [66]. In a worry regulation task with scripts, worry induction state elicited greater rostral ACC reactivity in geriatric GAD patients [67]. These findings suggest a link between abnormally increased ACC responsivity and pathological hypervigilance to worry-inducing situations in GAD patients. Greater ACC recruitment in GAD may reflect automatic emotion regulation [67] and introspective rumination [66] to overwhelming worry, as worry-inducing situations are more salient to GAD patients than to healthy individuals [46]. This interpretation aligns with cognitive neuroscience research that considers the ACC as a core component of a brain network for salience processing [68]. In addition, while listing worry topic items vs. neutral items, geriatric GAD patients showed exaggerated response in one area of the ACC (peak voxel: MNI $14,34,16)$ and dampened response in a more dorsal portion of the ACC (peak voxel: MNI 
$8,12,26)$, suggesting that subregions within the ACC may be affected differently by GAD pathophysiology [46]. Overall, findings with regards to ACC appears to largely depend on the type of task used; those that involve worry induction are consistently reporting greater ACC reactivity in GAD, while most other tasks (e.g., facial expressions, emotional images, fear conditioning) show decreased ACC reactivity in GAD.

\subsection{Prefrontal Cortex}

While PFC is generally understood to provide top-down, regulatory inputs to subcortical areas (e.g., amygdala) during affective processing [32], its major subregions, including vmPFC, vlPFC, dmPFC, and dlPFC, are suggested to play different functional roles as a component of a corticolimbic circuit [13]. For example, vmPFC regulates amygdala activity during fear conditioning [24], whereas vlPFC, dmPFC, and dlPFC are involved in the top-down control of the amygdala during the cognitive control of emotion [30]. It follows then that different PFC subregions are probed across fMRI studies of GAD, depending on the characteristics of the task.

During fear conditioning, converging evidence was found for reduced vmPFC reactivity in response to safety (or most dissimilar to threat) vs. threat signals in GAD patients $[65,69,70]$. In one such study, GAD patients also showed simultaneous increases in dIPFC activation in response to safety vs. threat signals [65]. These findings support the prediction that impaired vmPFC function in GAD is associated with the overgeneralization of fear. In addition, when listing or imagining items after a narrative instruction, GAD patients showed reduced vmPFC responses to worry/disorder-related vs. neutral stimuli $[46,47]$ while displaying greater vlPFC and dmPFC responses [47] compared to healthy individuals. In a non-emotional memory task, GAD patients showed reduced vmPFC reactivity while suppressing the memory of paired words than during retrieval conditioning [71]. Collectively, these findings offer a link between abnormally decreased vmPFC responsivity and GAD pathophysiology.

During an emotion regulation paradigm, GAD patients showed diminished dmPFC and dIPFC activity during the cognitive reappraisal of negative emotions, as well as reduced vlPFC reactivity when maintaining emotional responses [64]. Similarly, in other fMRI studies utilizing cognitive control tasks (e.g., emotional Stroop task, working memory task) in conjunction with emotional stimuli (e.g., affective words, anxiety-inducing pictures), GAD patients showed decreased dmPFC [72] and dIPFC [45,73-75] responses to emotional conflict. These findings are consistent with a meta-analysis of functional neuroimaging studies that focused on tasks involving cognitive control of emotion [30]. Furthermore, GAD patients exhibited decreased coupling with negative valence and high arousal in dmPFC and dlPFC when watching a 42 min video (an episode of Lost) with affective content [50]. When contemplating the likelihood of experiencing future events, GAD patients showed decreased activity in the rostral $\mathrm{MPFC}$, which is proximal to dmPFC, in response to high- vs. low-impact events [76]. Once again, a consistent picture was painted with regards to the functional abnormalities of dmPFC and dIPFC, such that their decreased responsivity was associated with GAD pathophysiology.

In contrast to the aforementioned findings that suggest an overall decrease in the degree of regulatory PFC signals in GAD, some studies have reported that GAD patients exhibited elevated PFC region responses to threat-related stimuli. Compared to healthy individuals, both adult and pediatric GAD patients showed increased PFC responses (e.g., dlPFC, vlPFC, vPFC, and mPFC) to negative emotional stimuli (e.g., anxiety-inducing words, anxiety-inducing pictures, unpleasant pictures, fearful faces, and angry faces) in various task situations [52,77-81]. Taken together, these findings further highlight the importance of task heterogeneity in fMRI studies when considering functional abnormalities of the PFC in GAD. Studies demonstrating either exaggerated or blunted PFC responsivity in GAD are not at odds with one another; rather, they are readily explained by the differences within the experimental paradigm employed for each fMRI task. Overall, tasks tapping into the overgeneralization of fear consistently produce reduced vmPFC 
activity, while those requiring cognitive control of emotion are consistently associated with decreased dmPFC and dIPFC activity. Other tasks that involve viewing or responding to negative emotional stimuli may elicit exaggerated PFC responses in GAD.

\subsection{Other Brain Regions}

Outside of the brain regions typically considered to be components of a corticolimbic circuit for affective processing, functional abnormalities of the insula and the hippocampus are often reported in GAD (see [4] for meta-analyses). GAD patients showed diminished insula reactivity when they were asked to cognitively reappraise [44] or maintain [64] negative emotions during an emotion regulation paradigm. In a cognitive control task in which participants contemplated likelihoods of future events that may occur, GAD patients exhibited weaker insula reactivity to high-impact vs. low-impact situations [76]. Meanwhile, in a task that requires the subjects to count their own heartbeat and auditory tone, GAD patients displayed greater insula reactivity to their heartbeat vs. pure tone [82]. The elevated response of the insula to the sound of one's own heartbeat implies a high level of interoceptive awareness [83]. A few studies using emotionally charged stimuli reported exaggerated insula reactivity in both adult and geriatric GAD patients. For example, in response to emotionally negative stimuli (e.g., unpleasant images, angry and fearful faces, and worry topic items), GAD patients showed increased insula reactivity compared to healthy controls $[46,54,77]$. In addition, during a reinforcement learning task, exaggerated insula activity was found in response to both gain and loss situations in GAD patients [84]. In an emotion detection task, however, GAD patients exhibited decreased insula response to both fearful and happy faces vs. neutral faces [62].

In studies utilizing fear conditioning, GAD patients exhibited diminished hippocampal reactivity to threat signals compared to healthy controls $[65,85]$. The impaired responsivity of the hippocampus in GAD patients, in conjunction with the vmPFC, may explain their difficulty in discriminating safety signals from threat signals, as well as overall vulnerability to threat-related stimuli. In addition, a few studies using emotionally charged stimuli showed decreased hippocampus reactivity in GAD patients. For example, in response to anxiety-inducing words during an explicit memory task, GAD patients showed dampened hippocampal activity compared to their healthy counterparts $[80,81]$. Processing happy and fearful faces (vs. neutral faces) also elicited weaker hippocampal reactivity in GAD patients [62]. In contrast, while performing memory tasks, GAD patients displayed exaggerated left hippocampal response to negative image distractors compared to healthy controls $[74,75]$. It is worth mentioning that the opposite activation patterns of the hippocampus appeared across a series of studies conducted by the same research group, utilizing a similar experimental paradigm with some notable differences. A likely explanation for the seemingly opposite effect is that, when GAD patients were presented with anxiety-inducing stimuli that served as a distractor to the main task, their hippocampal activity was increased; when asked to explicitly pay attention to anxiety-inducing stimuli, their hippocampal activity was decreased. These results again illustrate the importance of considering task goals when interpreting the findings from fMRI research.

\section{Factors Contributing to the Mixed Findings in Task-Based fMRI Studies of GAD}

Overall, task-based fMRI studies of GAD showed converging evidence for exaggerated amygdala responsivity and reduced PFC reactivity, aligning with the popular framework represented by the corticolimbic circuit, but they also displayed some mixed findings (Figure 1). Factors that may contribute to this observation include (1) the heterogeneous nature of the tasks used in fMRI research, (2) limited sample size at an individual study level, and (3) the reliability of task-evoked amygdala BOLD signals. Among these issues, task heterogeneity is not a concern on the researcher's part. fMRI tasks can, and should be, tailored to meet the specific goals of each individual study. Rather, readers would need to exercise caution when drawing conclusions, as the interpretation of data must be carefully done within the boundaries of the study context. That being said, for future investigations, 
it may be worth considering the active utilization of tasks that focuses on uncertainty, as GAD is hypothesized to be sensitive to uncertain information. As an example, separating the presentation of fearful (uncertain threat) vs. angry (certain threat) faces during an fMRI task would likely yield more promising results with increased specificity and precision [55].

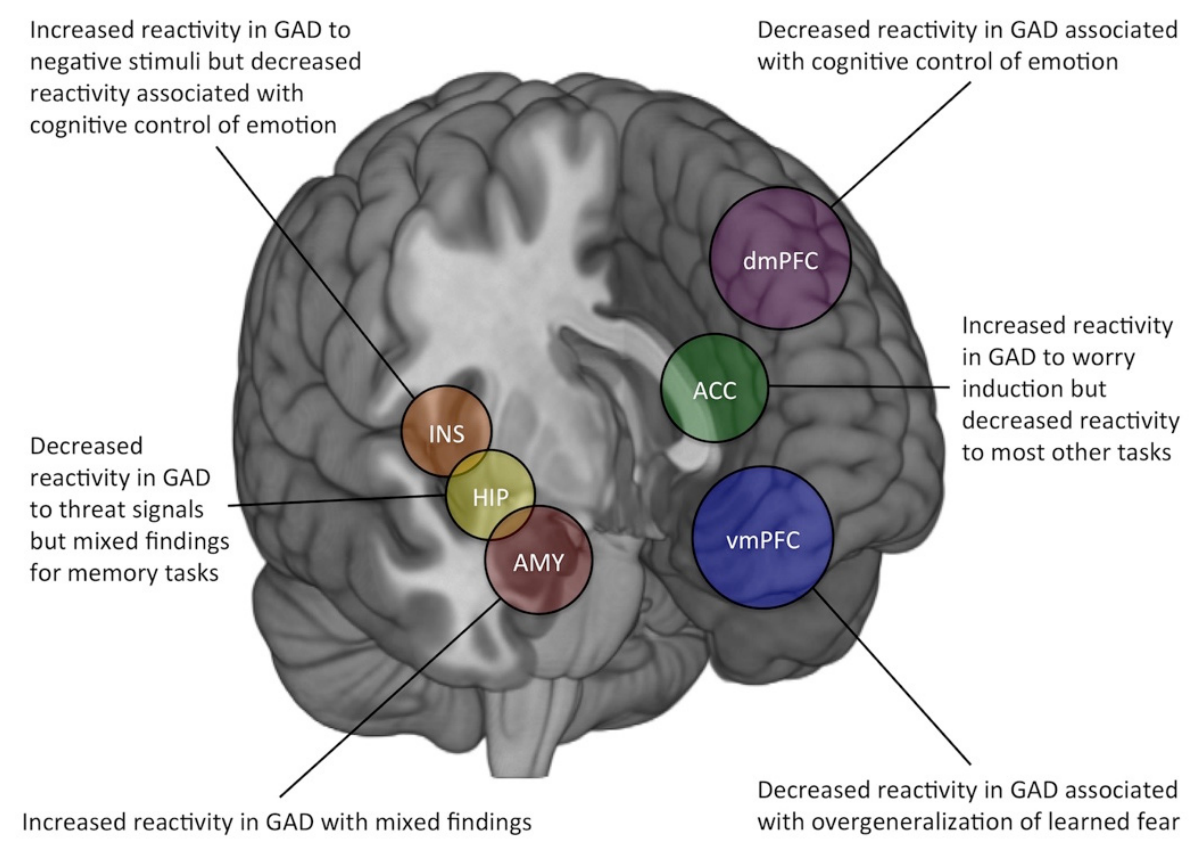

Figure 1. Summary of the findings from task-based fMRI studies of generalized anxiety disorder (GAD), focusing on blood oxygen level-dependent (BOLD) signal changes within the corticolimbic circuit and other brain regions. Overall, the results were largely dependent upon the task used to elicit regional brain activity. ACC: anterior cingulate cortex; AMY: amygdala; dmPFC: dorsomedial prefrontal cortex; HIP: hippocampus; INS: insula; vmPFC: ventromedial prefrontal cortex.

Limited sample size is, potentially, a more serious issue that needs to be addressed by researchers. Currently, the average sample size of the studies included in this review is approximately 20 subjects for both GAD and healthy control groups, and the study with the greatest number of GAD patients had 46, which is generally in line with the clinical fMRI literature [8]. This is a suboptimal number for fMRI research, given that clinical studies inherently deal with between-subject variability [86]. Results from underpowered studies would likely be unreliable and could negatively impact the replicability of the findings $[87,88]$, potentially contributing to the mixed findings in the literature. Of course, practical issues such as limited resources prevent individual research groups and labs from performing large-scale data collection and analysis. As such, perhaps a multisite collaborative effort such as the Enhancing NeuroImaging Genetics through MetaAnalysis (ENIGMA) consortium [5] may be a useful means to counter the drawbacks of underpowered individual studies, as well as gain a clearer picture of abnormal brain functional responsivity patterns in GAD. For such efforts to achieve greater heights, the development of specific tasks and experimental paradigms that are tailored to probe GAD psychopathology would be useful.

Lastly, it has been recently suggested that BOLD responses from emotional tasks, especially from limbic regions, have poor psychometric properties (e.g., test-retest reliability) $[7,8]$. While the current review found generally consistent findings concerning the amygdala, this warrants attention for future task-based fMRI investigations, as the issue of reliability becomes exacerbated by small sample sizes [88]. Possible approaches to circumvent this issue include ensuring external factors that affect BOLD signals are accounted for as much as possible as well as analyzing multivariate activity patterns in addition to traditional regional activity changes [89]. 


\section{Conclusions}

In summary, we found that task-based fMRI studies of GAD have frequently targeted three brain regions that are components of the corticolimbic circuit: the amygdala, anterior cingulate cortex, and prefrontal cortex. The amygdala showed overall hyperactivity tendency to negative emotional stimuli in GAD. Increased activation in the ACC has been observed consistently in response to worry induction, while the opposite pattern was found in most other task paradigms (e.g., facial expressions, emotional images, and fear conditioning). In GAD, negative emotional stimuli elicited greater PFC reactivity in general while fear overgeneralization tasks reported dampened responses in the vmPFC specifically. In particular, emotion regulation tasks produced reduced dmPFC and dlPFC activity in GAD patients. In other brain regions, the insula showed exaggerated responses to negative emotional stimuli and lesser reactivity associated with emotion regulation in GAD. In addition, GAD patients exhibited diminished hippocampal activity to threat signals and the opposite reactivity effect was found in memory tasks. Taken together, the current GAD literature using task-based fMRI shows generally converging results, along with some mixed findings. The latter could be explained by a combination of task heterogeneity, limited sample size, and the suboptimal reliability of some task-evoked BOLD signals. Overcoming these potential problems in task-based fMRI research would further our understanding of the pathophysiology of GAD, which, in turn, can contribute to the development of a promising biomarker.

Author Contributions: N.K. performed the literature search and drafted the manuscript. M.J.K. designed the study and edited the manuscript. All authors have read and agreed to the published version of the manuscript.

Funding: This research was supported by the BK21 FOUR (Fostering Outstanding Universities for Research) funded by the Ministry of Education (MOE) and the National Research Foundation (NRF) of South Korea.

Conflicts of Interest: The authors declare no conflict of interest.

\section{References}

1. Comer, J.S.; Kendall, P.C.; Franklin, M.E.; Hudson, J.L.; Pimentel, S.S. Obsessing/worrying about the overlap between obsessivecompulsive disorder and generalized anxiety disorder in youth. Clin. Psychol. Rev. 2004, 24, 663-683. [CrossRef]

2. Mineka, S.; Hendersen, R.W. Controllability and predictability in acquired motivation. Annu. Rev. Psychol. 1985, 36, 495-529. [CrossRef]

3. Ruscio, A.M.; Gentes, E.L.; Jones, J.D.; Hallion, L.S.; Coleman, E.S.; Swendsen, J. Rumination predicts heightened responding to stressful life events in major depressive disorder and generalized anxiety disorder. J. Abnorm. Psychol. 2015, 124, 17-26. [CrossRef] [PubMed]

4. Kabat-Zinn, J.; Massion, A.O.; Kristeller, J.; Peterson, L.G.; Fletcher, K.E.; Pbert, L.; Lenderking, W.R.; Santorelli, S.F. Effectiveness of a meditation-based stress reduction program in the treatment of anxiety disorder. Am. J. Psychiatry 1992, 149, 936-943. [PubMed]

5. Zugman, A.; Harrewijn, A.; Cardinale, E.M.; Zwiebel, H.; Freitag, G.F.; Werwath, K.E.; Bas-Hoogendam, J.M.; Groenewold, N.A.; Aghajani, M.; Hilbert, K.; et al. Mega-analysis methods in ENIGMA: The experience of the generalized anxiety disorder working group. Hum. Brain Mapp. 2020. [CrossRef] [PubMed]

6. Kolesar, T.; Bilevicius, E.; Wilson, A.D.; Kornelsen, J. Systematic review and meta-analyses of neural structural and functional differences in generalized anxiety disorder and healthy controls using magnetic resonance imaging. NeuroImage Clin. 2019, 24, 102016. [CrossRef] [PubMed]

7. Madonna, D.; Delvecchio, G.; Soares, J.C.; Brambilla, P. Structural and functional neuroimaging studies in generalized anxiety disorder: A systematic review. Braz. J. Psychiatry 2019, 41, 336-362. [CrossRef] [PubMed]

8. Szucs, D.; Ioannidis, J.P. Sample size evolution in neuroimaging research: An evaluation of highly-cited studies (1990-2012) and of latest practices (2017-2018) in high-impact journals. NeuroImage 2020, 221, 117164. [CrossRef] [PubMed]

9. Elliott, M.L.; Knodt, A.R.; Ireland, D.; Morris, M.L.; Poulton, R.; Ramrakha, S.; Sison, M.L.; Moffitt, T.E.; Caspi, A.; Hariri, A.R. What is the test-retest reliability of common task-functional MRI measures? New empirical evidence and a meta-analysis. Psychol. Sci. 2020, 31, 792-806. [CrossRef]

10. Infantolino, Z.P.; Luking, K.R.; Sauder, C.K.; Curtin, J.J.; Hajcak, G. Robust is not necessarily reliable: From within-subjects fMRI contrasts to between-subjects comparisons. NeuroImage 2018, 173, 146-152. [CrossRef] 
11. Bishop, S.J. Neurocognitive mechanisms of anxiety: An integrative account. Trends Cogn. Sci. 2007, 11, 307-316. [CrossRef] [PubMed]

12. Grupe, D.W.; Nitschke, J.B. Uncertainty and anticipation in anxiety: An integrated neurobiological and psychological perspective. Nat. Rev. Neurosci. 2013, 14, 488-501. [CrossRef] [PubMed]

13. Kim, M.J.; Loucks, R.A.; Palmer, A.L.; Brown, A.C.; Solomon, K.M.; Marchante, A.N.; Whalen, P.J. The structural and functional connectivity of the amygdala: From normal emotion to pathological anxiety. Behav. Brain Res. 2011, 223, 403-410. [CrossRef] [PubMed]

14. Aggleton, J.P. The Amygdala: Neurobiological Aspects of Emotion, Memory, and Mental Dysfunction; Wiley-Liss, Inc.: New York, NY, USA, 1992.

15. Whalen, P.J.; Phelps, E.A. The Human Amygdala; The Guilford Press: New York, NY, USA, 2009.

16. LeDoux, J.E. Emotion circuits in the brain. Annu. Rev. Neurosci. 2000, 23, 155-184. [CrossRef] [PubMed]

17. Adolphs, R.; Tranel, D.; Damasio, H.; Damasio, A.R. Fear and the human amygdala. J. Neurosci. 1995, 15, 5879-5891. [CrossRef]

18. Davis, M.; Whalen, P.J. The amygdala: Vigilance and emotion. Mol. Psychiatry 2001, 6, 13-34. [CrossRef]

19. Hariri, A.R.; Mattay, V.S.; Tessitore, A.; Kolachana, B.; Fera, F.; Goldman, D.; Egan, M.F.; Weinberger, D.R. Serotonin transporter genetic variation and the response of the human amygdala. Science 2002, 297, 400-403. [CrossRef]

20. Jin, J.; Zelano, C.; Gottfried, J.A.; Mohanty, A. Human amygdala represents the complete spectrum of subjective valence. J. Neurosci. 2015, 35, 15145-15156. [CrossRef] [PubMed]

21. Wilson-Mendenhall, C.D.; Barrett, L.F.; Barsalou, L.W. Neural evidence that human emotions share core affective properties. Psychol. Sci. 2013, 24, 947-956. [CrossRef]

22. Adolphs, R. What does the amygdala contribute to social cognition? Ann. N. Y. Acad. Sci. 2010, 1191, 42-61. [CrossRef] [PubMed]

23. Ghashghaei, H.T.; Hilgetag, C.C.; Barbas, H. Sequence of information processing for emotions based on the anatomic dialogue between prefrontal cortex and amygdala. NeuroImage 2007, 34, 905-923. [CrossRef]

24. Milad, M.R.; Quirk, G.J. Neurons in medial prefrontal cortex signal memory for fear extinction. Nature 2002, 420, 70-74. [CrossRef]

25. McRae, K.; Gross, J.J. Emotion regulation. Emotion 2020, 20, 1-9. [CrossRef] [PubMed]

26. Fernandez, K.C.; Jazaieri, H.; Gross, J.J. Emotion regulation: A transdiagnostic perspective on a new RDoC domain. Cognit. Ther. Res. 2016, 40, 426-440. [CrossRef] [PubMed]

27. Morawetz, C.; Riedel, M.C.; Salo, T.; Berboth, S.; Eickoff, S.B.; Laird, A.R.; Kohn, N. Multiple large-scale neural networks underlying emotion regulation. Neurosci. Biobehav. Rev. 2020, 116, 382-395. [CrossRef]

28. Ochsner, K.N.; Gross, J.J. The cognitive control of emotion. Trends Cogn. Sci. 2005, 9, 242-249. [CrossRef]

29. Denny, B.T.; Inhoff, M.C.; Zerubavel, N.; Davachi, L.; Ocshner, K.N. Getting over it: Long-lasting effects of emotion regulation on amygdala response. Psychol. Sci. 2015, 26, 1377-1388. [CrossRef] [PubMed]

30. Buhle, J.T.; Silvers, J.A.; Wager, T.D.; Lopez, R.; Onyemekwu, C.; Kober, H.; Weber, J.; Ochsner, K.N. Cognitive reappraisal of emotion: A meta-analysis of human neuroimaging studies. Cereb. Cortex 2014, 24, 2981-2990. [CrossRef] [PubMed]

31. Hartley, C.A.; Phelps, E.A. Changing fear: The neurocircuitry of emotion regulation. Neuropsychopharmacology 2009, 35, 136-146. [CrossRef]

32. Quirk, G.J.; Beer, J.S. Prefrontal involvement in the regulation of emotion: Convergence of rat and human studies. Curr. Opin. Neurobiol. 2006, 16, 723-727. [CrossRef]

33. Barbas, H.; De Olmos, J. Projections from the amygdala to basoventral and mediodorsal prefrontal regions in the rhesus monkey. J. Comp. Neurol. 1990, 300, 549-571. [CrossRef]

34. Carmichael, S.T.; Price, J.L. Limbic connections of the orbital and medial prefrontal cortex in macaque monkeys. J. Comp. Neurol. 1995, 363, 615-641. [CrossRef]

35. Aggleton, J.P.; Burton, M.J.; Passingham, R.E. Cortical and subcortical afferents to the amygdala of the rhesus monkey (Macaca mulatta). Brain Res. 1980, 190, 347-368. [CrossRef]

36. Calhoon, G.G.; Tye, K.M. Resolving the neural circuits of anxiety. Nat. Neurosci. 2015, 18, 1394-1404. [CrossRef] [PubMed]

37. Tovote, P.; Fadok, J.P.; Lüthi, A. Neuronal circuits for fear and anxiety. Nat. Rev. Neurosci. 2015, 16, 317-331. [CrossRef]

38. Etkin, A.; Wager, T.D. Functional neuroimaging of anxiety: A meta-analysis of emotional processing in PTSD, social anxiety disorder, and specific phobia. Am. J. Psychiatry 2007, 164, 1476-1488. [CrossRef] [PubMed]

39. Shin, L.M.; Liberzon, I. The neurocircuitry of fear, stress, and anxiety. Neuropsychopharmacology 2010, 35, 169-191. [CrossRef] [PubMed]

40. Bishop, S.; Duncan, J.; Brett, M.; Lawrence, A.D. Prefrontal cortical function and anxiety: Controlling attention to threat-related stimuli. Nat. Neurosci. 2004, 7, 184-188. [CrossRef] [PubMed]

41. Kim, M.J.; Chey, J.; Chung, A.; Bae, S.; Khang, H.; Ham, B.; Yoon, S.J.; Jeong, D.-U.; Lyoo, I.K. Diminished rostral anterior cingulate activity in response to threat-related events in posttraumatic stress disorder. J. Psychiatry Res. 2008, 42, 268-277. [CrossRef] [PubMed]

42. Hariri, A.R.; Mattay, V.S.; Tessitore, A.; Fera, F.; Weinberger, D.R. Neocortical modulation of the amygdala response to fearful stimuli. Biol. Psychiatry 2003, 53, 494-501. [CrossRef]

43. Pezawas, L.; Meyer-Lindenberg, A.; Drabant, E.M.; Verchinski, B.A.; Munoz, K.E.; Kolachana, B.S.; Egan, M.F.; Mattay, V.S.; Hariri, A.R.; Weinberger, D.R. 5-HTTLPR polymorphism impacts human cingulate-amygdala interactions: A genetic susceptibility mechanism for depression. Nat. Neurosci. 2005, 8, 828-834. [CrossRef] 
44. Fitzgerald, J.M.; Phan, K.L.; Kennedy, A.E.; Shankman, S.A.; Langenecker, S.A.; Klumpp, H. Prefrontal and amygdala engagement during emotional reactivity and regulation in generalized anxiety disorder. J. Affect. Disord. 2017, 218, 398-406. [CrossRef] [PubMed]

45. Price, R.B.; Eldreth, D.A.; Mohlman, J. Deficient prefrontal attentional control in late-life generalized anxiety disorder: An fMRI investigation. Transl. Psychiatry 2011, 1, e46. [CrossRef]

46. Mohlman, J.; Eldreth, D.A.; Price, R.B.; Staples, A.M.; Hanson, C. Prefrontal-limbic connectivity during worry in older adults with generalized anxiety disorder. Aging Ment. Health 2017, 21, 426-438. [CrossRef]

47. Buff, C.; Schmidt, C.; Brinkmann, L.; Gathmann, B.; Tupak, S.; Straube, T. Directed threat imagery in generalized anxiety disorder. Psychol. Med. 2018, 48, 617-628. [CrossRef] [PubMed]

48. Nitschke, J.B.; Sarinopoulos, I.; Oathes, D.J.; Johnstone, T.; Whalen, P.J.; Davidson, R.J.; Kalin, N.H. Anticipatory activation in the amygdala and anterior cingulate in generalized anxiety disorder and prediction of treatment response. Am. J. Psychiatry 2009, 166, 302-310. [CrossRef] [PubMed]

49. Blair, K.S.; Geraci, M.; Smith, B.W.; Hollon, N.; DeVido, J.; Otero, M.; Pine, D.S. Reduced dorsal anterior cingulate cortical activity during emotional regulation and top-down attentional control in generalized social phobia, generalized anxiety disorder, and comorbid generalized social phobia/generalized anxiety disorder. Biol. Psychiatry 2012, 72, 476-482. [CrossRef]

50. Carlson, J.M.; Rubin, D.; Mujica-Parodi, L.R. Lost emotion: Disrupted brain-based tracking of dynamic affective episodes in anxiety and depression. Psychiatry Res. Neuroimaging 2017, 260, 37-48. [CrossRef] [PubMed]

51. Yassa, M.A.; Hazlett, R.L.; Stark, C.E.L.; Hoehn-Saric, R. Functional MRI of the amygdala and bed nucleus of the stria terminalis during conditions of uncertainty in generalized anxiety disorder. J. Psychiatr. Res. 2012, 46, 1045-1052. [CrossRef] [PubMed]

52. McClure, E.B.; Monk, C.S.; Nelson, E.E.; Parrish, J.M.; Adler, A.; Blair, R.J.R.; Fromm, S.; Charney, D.S.; Leibenluft, E.; Ernst, M.; et al. Abnormal attention modulation of fear circuit function in pediatric generalized anxiety disorder. Arch. Gen. Psychiatry 2007, 64, 97-106. [CrossRef] [PubMed]

53. Monk, C.S.; Telzer, E.H.; Mogg, K.; Bradley, B.P.; Mai, X.; Louro, H.M.C.; Chen, G.; McClure, E.B.; Ernst, M.; Pine, D.S. Amygdala and ventrolateral prefrontal cortex activation to masked angry faces in children and adolescents with generalized anxiety disorder. Arch. Gen. Psychiatry 2008, 65, 568-576. [CrossRef] [PubMed]

54. Fonzo, G.A.; Ramsawh, H.J.; Flagan, T.M.; Sullivan, S.G.; Simmons, A.N.; Paulus, M.P.; Stein, M.B. Cognitive-behavioral therapy for generalized anxiety disorder is associated with attenuation of limbic activation to threat-related facial emotions. J. Affect. Disord. 2014, 169, 76-85. [CrossRef] [PubMed]

55. Fonzo, G.A.; Ramsawh, H.J.; Flagan, T.M.; Sullivan, S.G.; Letamendi, A.; Simmons, A.N.; Paulus, M.P.; Stein, M.B. Common and disorder-specific neural responses to emotional faces in generalised anxiety, social anxiety and panic disorders. Br. J. Psychiatry 2015, 206, 206-215. [CrossRef] [PubMed]

56. Hariri, A.R.; Whalen, P.J. The amygdala: Inside and out. F1000 Biol. Rep. 2011, 3, 2. [CrossRef]

57. Whalen, P.J. Fear, vigilance, and ambiguity: Initial neuroimaging studies of the human amygdala. Curr. Dir. Psychol. Sci. 1998, 7, 177-188. [CrossRef]

58. Hölzel, B.K.; Hoge, E.A.; Greve, D.N.; Gard, T.; Creswell, J.D.; Brown, K.W.; Barrett, L.F.; Schwartz, C.; Vaitl, D.; Lazar, S.W. Neural mechanisms of symptom improvements in generalized anxiety disorder following mindfulness training. NeuroImage Clin. 2013, 2, 448-458. [CrossRef] [PubMed]

59. Blair, K.; Shaywitz, J.; Smith, B.W.; Rhodes, R.; Geraci, M.; Jones, M.; McCaffrey, D.; Vythilingam, M.; Finger, E.; Mondillo, K.; et al. Response to emotional expressions in generalized social phobia and generalized anxiety disorder: Evidence for separate disorders. Am. J. Psychiatry 2008, 165, 1193-1202. [CrossRef]

60. Etkin, A.; Egner, T.; Peraza, D.M.; Kandel, E.R.; Hirsch, J. Resolving emotional conflict: A role for the rostral anterior cingulate cortex in modulating activity in the amygdala. Neuron 2006, 51, 871-882. [CrossRef]

61. Bush, G.; Luu, P.; Posner, M.I. Cognitive and emotional influences in anterior cingulate cortex. Trends Cogn. Sci. 2000, 4, 215-222. [CrossRef]

62. Li, J.; Zhong, Y.; Ma, Z.; Wu, Y.; Pang, M.; Wang, C.; Liu, N.; Wang, C.; Zhang, N. Emotion reactivity-related brain network analysis in generalized anxiety disorder: A task fMRI study. BMC Psychiatry 2020, 20, 429. [CrossRef]

63. Palm, M.E.; Elliott, R.; McKie, S.; Deakin, J.F.W.; Anderson, I.M. Attenuated responses to emotional expressions in women with generalized anxiety disorder. Psychol. Med. 2011, 41, 1009-1018. [CrossRef] [PubMed]

64. Ball, T.M.; Ramsawh, H.J.; Campbell-Sills, L.; Paulus, M.P.; Stein, M.B. Prefrontal dysfunction during emotion regulation in generalized anxiety and panic disorders. Psychol. Med. 2013, 43, 1475-1486. [CrossRef] [PubMed]

65. Via, E.; Fullana, M.A.; Goldberg, X.; Tinoco-González, D.; Martínez-Zalacaín, I.; Soriano-Mas, C.; Davey, C.G.; Menchón, J.M.; Straube, B.; Kircher, T.; et al. Ventromedial prefrontal cortex activity and pathological worry in generalised anxiety disorder. Br. J. Psychiatry 2018, 213, 437-443. [CrossRef] [PubMed]

66. Paulesu, E.; Sambugaro, E.; Torti, T.; Danelli, L.; Ferri, F.; Scialfa, G.; Sberna, M.; Ruggiero, G.M.; Bottini, G.; Sassaroli, S. Neural correlates of worry in generalized anxiety disorder and in normal controls: A functional MRI study. Psychol. Med. 2010, 40, 117-124. [CrossRef]

67. Andreescu, C.; Gross, J.J.; Lenze, E.; Edelman, K.D.; Snyder, S.; Tanase, C.; Aizenstein, H. Altered cerebral blood flow patterns associated with pathologic worry in the elderly. Depress. Anxiety 2011, 28, 202-209. [CrossRef] [PubMed] 
68. Seeley, W.W.; Menon, V.; Schatzberg, A.F.; Keller, J.; Glover, G.H.; Kenna, H.; Reiss, A.L.; Greicius, M.D. Dissociable intrinsic connectivity networks for salience processing and executive control. J. Neurosci. 2007, 27, 2349-2356. [CrossRef]

69. Cha, J.; Greenberg, T.; Carlson, J.M.; DeDora, D.J.; Hajcak, G.; Mujica-Parodi, L.R. Circuit-wide structural and functional measures predict ventromedial prefrontal cortex fear generalization: Implications for generalized anxiety disorder. J. Neurosci. 2014, 34, 4043-4053. [CrossRef]

70. Greenberg, T.; Carlson, J.M.; Cha, J.; Hajcak, G.; Mujica-Parodi, L.R. Ventromedial prefrontal cortex reactivity is altered in generalized anxiety disorder during fear generalization. Depress. Anxiety 2013, 30, 242-250. [CrossRef]

71. Diwadkar, V.A.; Re, M.; Cecchetto, F.; Garzitto, M.; Piccin, S.; Bonivento, C.; Maieron, M.; D’Agostini, S.; Balestreri, M.; Brambilla, P. Attempts at memory control induce dysfunctional brain activation profiles in generalized anxiety disorder: An exploratory fMRI study. Psychiatry Res. Neuroimaging 2017, 266, 42-52. [CrossRef] [PubMed]

72. Etkin, A.; Prater, K.E.; Hoeft, F.; Menon, V.; Schatzberg, A.F. Failure of anterior cingulate activation and connectivity with the amygdala during implicit regulation of emotional processing in generalized anxiety disorder. Am. J. Psychiatry 2010, 167, 545-554. [CrossRef]

73. Moon, C.M.; Jeong, G.W. Functional and morphological alterations associated with working memory dysfunction in patients with generalized anxiety disorder. Acta Radiol. 2017, 58, 344-352. [CrossRef] [PubMed]

74. Moon, C.M.; Jeong, G.W. Functional neuroanatomy on the working memory under emotional distraction in patients with generalized anxiety disorder. Psychiatry Clin. Neurosci. 2015, 69, 609-619. [CrossRef]

75. Moon, C.M.; Sundaram, T.; Choi, N.G.; Jeong, G.W. Working memory dysfunction associated with brain functional deficits and cellular metabolic changes in patients with generalized anxiety disorder. Psychiatry Res. Neuroimaging 2016, 254, 137-144. [CrossRef]

76. Blair, K.S.; Otero, M.; Teng, C.; Geraci, M.; Ernst, M.; Blair, R.J.R.; Pine, D.S.; Grillon, C. Reduced optimism and a heightened neural response to everyday worries are specific to generalized anxiety disorder, and not seen in social anxiety. Psychol. Med. 2017, 47, 1806-1815. [CrossRef] [PubMed]

77. Buff, C.; Brinkmann, L.; Neumeister, P.; Feldker, K.; Heitmann, C.; Gathmann, B.; Andor, T.; Straube, T. Specifically altered brain responses to threat in generalized anxiety disorder relative to social anxiety disorder and panic disorder. NeuroImage Clin. 2016, 12, 698-706. [CrossRef] [PubMed]

78. Moon, C.M.; Yang, J.C.; Jeong, G.W. Functional neuroanatomy associated with the interaction between emotion and cognition in explicit memory tasks in patients with generalized anxiety disorder. Acta Radiol. 2017, 58, 98-106. [CrossRef] [PubMed]

79. Moon, C.M.; Yang, J.C.; Jeong, G.W. Explicit verbal memory impairments associated with brain functional deficits and morphological alterations in patients with generalized anxiety disorder. J. Affect. Disord. 2015, 186, 328-336. [CrossRef]

80. Strawn, J.R.; Bitter, S.M.; Weber, W.A.; Chu, W.J.; Whitsel, R.M.; Adler, C.; Cerullo, M.A.; Eliassen, J.; Strakowski, S.M.; Delbello, M.P. Neurocircuitry of generalized anxiety disorder in adolescents: A pilot functional neuroimaging and functional connectivity study. Depress. Anxiety 2012, 29, 939-947. [CrossRef]

81. Monk, C.S.; Nelson, E.E.; McClure, E.B.; Mogg, K.; Bradley, B.P.; Leibenluft, E.; Blair, R.J.R.; Chen, G.; Charney, D.S.; Ernst, M.; et al. Ventrolateral prefrontal cortex activation and attentional bias in response to angry faces in adolescents with generalized anxiety disorder. Am. J. Psychiatry 2006, 163, 1091-1097. [CrossRef] [PubMed]

82. Cui, H.; Zhang, B.; Li, W.; Li, H.; Pang, J.; Hu, Q.; Zhang, L.; Tang, Y.; Yang, Z.; Wang, J.; et al. Insula shows abnormal task-evoked and resting-state activity in first-episode drug-naïve generalized anxiety disorder. Depress. Anxiety 2020, 37, 632-644. [CrossRef]

83. Tan, Y.; Wei, D.; Zhang, M.; Yang, J.; Jelincic, V.; Qiu, J. The role of mid-insula in the relationship between cardiac interoceptive attention and anxiety: Evidence from an fMRI study. Sci. Rep. 2018, 8, 17280. [CrossRef] [PubMed]

84. Laufer, O.; Israeli, D.; Paz, R. Behavioral and neural mechanisms of overgeneralization in anxiety. Curr. Biol. 2016, 26, 713-722 [CrossRef] [PubMed]

85. Cha, J.; Greenberg, T.; Song, I.; Blair Simpson, H.; Posner, J.; Mujica-Parodi, L.R. Abnormal hippocampal structure and function in clinical anxiety and comorbid depression. Hippocampus 2016, 26, 545-553. [CrossRef] [PubMed]

86. Dubois, J.; Adolphs, R. Building a science of individual differences from fMRI. Trends Cogn. Sci. 2016, 20, 425-443. [CrossRef] [PubMed]

87. Grady, C.L.; Rieck, J.R.; Nichol, D.; Rodrigue, K.M.; Kennedy, K.M. Influence of sample size and analytic approach on stability and interpretation of brain-behavior correlations in task-related fMRI data. Hum. Brain Mapp. 2021, 42, 204-219. [CrossRef]

88. Turner, B.O.; Paul, E.J.; Miller, M.B.; Barbey, A.K. Small sample sizes reduce the replicability of task-based fMRI studies. Commun. Biol. 2018, 1, 62. [CrossRef]

89. Kragel, P.A.; Han, X.; Kraynak, T.E.; Gianaros, P.J.; Wager, T.D. Functional MRI can be highly reliable, but it depends on what you measure: A Commentary on Elliott et al. (2020). Psychol. Sci. 2021. [CrossRef] 